\title{
Vascular involvement in chronic thromboembolic pulmonary hypertension is associated with spirometry obstructive impairment
}

Asako Yanagisawa ( $\square$ axsa4820@chiba-u.jp )

Chiba University

Akira Naito

Chiba University

Takayuki-Jujo Sanada

Chiba University

Nobuhiro Tanabe

Chibaken Saiseikai Narashino Hospital

Keiichi Ishida

Chiba University

Goro Matsumiya

Chiba University

Rika Suda

Chibaken Saiseikai Narashino Hospital

Hajime Kasai

Chiba University

Ayumi Sekine

Chiba University

Toshihiko Sugiura

Chiba University

Ayako Shigeta

Chiba University

Seiichiro Sakao

Chiba University

Koichiro Tatsumi

Chiba University

Takuji Suzuki

Chiba University 
Keywords: Chronic Thromboembolic pulmonary hypertension, obstructive ventilatory impairment, Respiratory impedance, CT angiography

Posted Date: September 7th, 2021

DOI: https://doi.org/10.21203/rs.3.rs-871334/v1

License: (c) (i) This work is licensed under a Creative Commons Attribution 4.0 International License. Read Full License

Version of Record: A version of this preprint was published at BMC Pulmonary Medicine on December 1st, 2021. See the published version at https://doi.org/10.1186/s12890-021-01779-x. 


\section{Abstract \\ Background}

Chronic thromboembolic pulmonary hypertension (CTEPH) is a type of pulmonary hypertension caused by persistent thromboembolism of the pulmonary arteries. In clinical practice, CTEPH patients often show obstructive ventilatory impairment, even in the absence of a smoking history. Recent reports imply a tendency for CTEPH patients to have a lower $\mathrm{FEV}_{1.0}$; however, the mechanism underlying obstructive impairment remains unknown.

\section{Methods}

We retrospectively analyzed CTEPH patients who underwent a pulmonary function test (PFT) and respiratory impedance test to evaluate their exertional dyspnea during admission for right heart catheterization from January 2000 to December 2019. We excluded patients with a smoking history to rule out the effect of smoking on obstructive impairment.

\section{Results}

A total of 135 CTEPH patients were analyzed. The median $\mathrm{FEV}_{1.0} / \mathrm{FVC}$ was $76.0 \%, \% \mathrm{FEV}_{1.0}$ had a negative correlation with the mean pulmonary artery pressure (mPAP) and pulmonary vascular resistance (PVR) and the CT Angiogram (CTA) obstruction score. A multivariate regression analysis revealed that the CTA obstruction score was an independent factor of a lower $\% \mathrm{FEV}_{1.0}$. In the 54 patients who underwent pulmonary endarterectomy, $\% \mathrm{FEV}_{1.0}$ was improved in some cases and was not in some. Mean PAP largely decreased after PEA in the better \%FEV ${ }_{1.0}$ improved cases, suggesting that vascular involvement in CTEPH could be associated with spirometry obstructive impairment.

\section{Conclusion}

\%FEV ${ }_{1.0}$ had a significant correlation with the CTA obstruction score. Obstructive impairment might have an etiological relationship with vascular involvement. Further investigations could shed new light on the etiology of CTEPH.

\section{Background}

Chronic thromboembolic pulmonary hypertension (CTEPH) is a type of pulmonary hypertension caused by persistent thromboembolism of pulmonary arteries that fail to undergo complete thrombolysis after pulmonary thromboembolism (PTE) [1]. Multiple mechanisms are behind the occurrence of CTEPH. 
Several etiological factors, including infection, inflammation, and genetic susceptibility have been discussed as important pathogenetic factors [2-7], although some aspects remain unclear.

In clinical practice, CTEPH patients often show obstructive ventilatory impairment, even in the absence of a smoking history. A case report found that a CTEPH patient was misdiagnosed with bronchial asthma because of exertional dyspnea and a low $\mathrm{FEV}_{1.0}$ [8]. A recent report describing the pulmonary function test (PFT) findings of CTEPH patients showed that they tended to have a low FEV ${ }_{1.0}$ compared to healthy controls [9]. However, the relationship between the lung mechanics and hemodynamics is unclear.

In the present study, we hypothesized that some etiological component of CTEPH might affect the decrease in expiratory airflow. We evaluated the data of right heart catheterization (RHC), CT angiogram, respiratory function test of CTEPH patients.

\section{Methods}

\section{Study population}

The patients with CTEPH who underwent a PFT and respiratory impedance test to evaluate their exertional dyspnea during admission for RHC were enrolled from January 2000 to December 2019 at Chiba University Hospital. In this study the patients who underwent CT angiography for quantification of the pulmonary arterial thrombus obstruction were selected.

The patients who had a smoking history were excluded to rule out the effect of smoking on obstructive impairment. The criteria for the CTEPH diagnosis have been previously described [10]. CTEPH was defined as a mean pulmonary arterial pressure of $25 \mathrm{mmHg}$ and pulmonary capillary wedge pressure of $<15 \mathrm{mmHg}$ on RHC. Before the RHC diagnosis, patients received anticoagulation therapy for at least three months and underwent perfusion scintigraphy of the lung that showed a segmental blood flow distribution defect with no abnormality in the ventilation distribution.

\section{Right heart catheterization (RHC)}

A 7.5-Fr Swan-Ganz catheter (Edwards Lifesciences, Irvine, CA, USA) was used for RHC. The pulmonary artery wedge pressure and pressure in the right atrium, right ventricle, main pulmonary artery, and right or left pulmonary artery were evaluated. The cardiac output (CO) was measured according to the thermodilution method. The procedure was described in greater detail in a previous study [11]. We conducted $\mathrm{RHC}$ testing during the same admission period as spirometry and the respiratory impedance test.

\section{Evaluation of sub-segmental pulmonary thrombi by CT angiography}

Chronic thrombi within sub-segmental pulmonary arteries were quantified by enhanced CT scanning according to the modified methods of Qanadli [12], and the details were described previously [13]. Briefly; 
analyzing enhanced CT Angiogram (CTA) image of $0.5 \mathrm{~mm}$ thick, forty-two sub-segmental pulmonary arteries (twenty-two right-sided and twenty left-sided) were identified on each CT scan image and each sub-segmental artery was evaluated over the entire series of images. Each sub-segmental pulmonary artery was scored as follows: score 0 : no thrombi; score 1 : the artery was narrowed by chronic thrombi but contrast medium passed to distal areas; and score 2: the artery was obstructed by chronic thrombi and contrast medium did not pass to distal areas. The CTA obstruction score was defined as the total score of each sub-segmental score (maximum 84 point). Two investigators interpreted CT scan images in a blinded manner. To minimize bias, CTA obstruction scores were defined as the average value between the two investigators.

\section{Spirometry}

The spirometry method is described previously [14, 15]; in brief, a PFT was performed for each patient according to the method described in the ATS/ERS guidelines [16]. The pulmonary function parameters, including the vital capacity (VC), forced VC (FVC), and forced expiratory volume in one second $\left(\mathrm{FEV}_{1.0}\right)$, were measured by spirometry. The predicted values for $\mathrm{VC}, \mathrm{FVC}, \mathrm{FEV}_{1.0}, \mathrm{~V} 50$, V25, maximum midexpiratory flow (MMF), and peak expiratory flow (PEF) were determined based on reference values [17]. The total lung capacity and diffusion capacity for carbon monoxide (DLCO) were measured. DLCO was measured by the helium-dilution and single-breath methods, following the Japanese Respiratory Society guidelines [18].

\section{Respiratory impedance}

Respiratory impedance was measured using a commercially available multi-frequency forced oscillation technique (FOT) device (Masterscreen IOS; Erich Jaeger, Hoechberg, Germany), following the standard recommendation [19]. The FOT measurements were performed before spirometry with the subjects in the sitting position with their neck in a comfortable neutral posture and wearing a nose clip, their cheeks firmly supported during measurement. The impedance against the oscillatory frequency was obtained. The measured respiratory system impedance was divided into the respiratory system resistance (Rrs) and respiratory system reactance (Xrs). Rrs is frequently interpreted as the airway caliber. The Rrs at $5 \mathrm{~Hz}$ (R5) and $20 \mathrm{~Hz}$ (R20) and the difference between the R5 and R20 (R5 - R20) were recorded. Xrs reflects the elastic and inertial properties of the lung and thorax, Fres is the point at which Xrs $=0$ is referred to as a resonant frequency, and ALX is the integral of reactance from X5 to Fres. These oscillatory indices were measured during the whole breath cycle.

\section{Statistical analyses}

Wilcoxon's signed-rank test, Fisher's exact test, and a univariate regression analysis were used for comparisons between two parameters, where appropriate. The logistic regression model was used to calculate the adjusted odds ratio (OR) with the $95 \%$ confidence interval (Cl) for obstructive impairment associated with hemodynamics in CTEPH. A multivariate logistic regression analysis was performed to evaluate the factors associated with the decreased expiratory airflow. 
The results are presented as the mean \pm SEM or median with interquartile range (IQR). P-values $<0.05$ were considered statistically significant. All statistical analyses were performed using a commercially available software program (JMP 9.0.2, Japanese version; SAS Institute Inc., Tokyo, Japan).

\section{Result}

\section{Patients' characteristics}

The clinical characteristics and respiratory function of CTEPH patients are summarized in Tables 1 and 2. A total of 251 patients were diagnosed with CTEPH from 2000 to 2019, and the 90 patients with a smoking history were excluded as mentioned above. Finally, we analyzed 135 patients who had all dataset of PFT, RHC, and CT angiography.

Female patients outnumbered male patients (108: 27), and $41 \%$ of all patients had acute pulmonary embolism episode (Table 1). None of the patients enrolled in this study were on bronchodilator treatment.

\section{Spirometry and respiratory impedance test findings}

Obstructive ventilatory impairment was observed in 34/135 (25.2\%) with a cut-off value of FEV 1.0 /FVC (\%) of $70 \%$, and the overall median $\mathrm{FEV}_{1.0} / \mathrm{FVC}$ decreased to $76.0 \%$, which is close to the lower limit. The MMF, V50, and V25, which were effort-independent components during the end-expiratory portion of the flow-volume curve, were lower than their expected values. These results suggested the existence of peripheral airway obstruction, although there was no significant difference in the residual volume or total lung capacity (Table 2). Regarding the relationship between the spirometry and respiratory impedance test results, no correlation was noted between the \%FEV 1.0 / \%MMF and R5, R20, or R5-R20 (Additional File 1).

\section{Correlation between the PFT and pulmonary hemodynamic parameters}

We analyzed the correlation between the PFT parameters and the pulmonary hemodynamics (mPAP, PVR, cardiac index) / CTA obstruction score. Among the PFT parameters shown in Table 2, the \%FEV 1.0 was inversely correlated with mPAP, PVR and CTA obstruction score, and positively correlated with the cardiac index (Table 3, Fig. 1).

The respiratory impedance parameters were poorly correlated with the pulmonary hemodynamic parameters, while the R20 and X5 had mild correlation with the cardiac indices (Additional File 2).

When patients were divided into two groups according to the median $\% \mathrm{FEV}_{1.0}(83.6 \%)$, the mPAP, PVR, RAP, CRP, BNP, and CTA obstruction score values were significantly higher, while the cardiac index and systolic BP values were lower in the lower $\% \mathrm{FEV}_{1.0}$ group than in the higher \%FEV 1.0 group (Table 4).

\section{Logistic regression analyses of low $\% \mathrm{FEV}_{1.0}$}


Given the negative correlation noted between pulmonary arterial obstruction or pulmonary hemodynamics and the $\% \mathrm{FEV}_{1.0}$, we tried to identify the predictors of a low $\% \mathrm{FEV}_{1.0}$. Dividing the patients into two groups according to the median $\% \mathrm{FEV}_{1.0}(83.6 \%)$ as in Table 4 , a univariate logistic regression analysis showed that higher BW, higher BNP, higher mPAP, higher PVR, lower $\mathrm{Cl}$, higher RAP, higher CTA obstruction score were associated with a low $\% \mathrm{FEV}_{1.0}$ in $\mathrm{CTEPH}$ patients. A multivariate logistic regression analysis showed that higher CTA obstruction score was independent factors associated with a low \%FEV 1.0 (Table 5).

\section{Effect of pulmonary endarterectomy (PEA) on the PFT}

We analyzed the effect of PEA on the PFT to further assess the correlation between respiratory function and the pulmonary hemodynamics. The pulmonary hemodynamics and pulmonary function one year after PEA are reported in Additional File 3.

To examine whether it is relevant between vascular involvement and obstructive impairment change after PEA, responder and non-responder in \%FEV 1.0 were extracted from the 54 patients receiving PEA. The largest 20 cases regarding the value of $\% \mathrm{FEV}_{1.0}$ positive and negative difference before and after PEA was defined as responder and non-responder, respectively, and the difference in value was named as $\triangle \% \mathrm{FEV}_{1.0}$ (Fig. 2A). Mean PAP was better improved in the responders group compared to the nonresponders (Fig. 2B). In 29 patients in whose CTA obstruction score could be assessed postoperatively, $\triangle \mathrm{CTA}$ obstruction score and $\Delta \% \mathrm{FEV}_{1.0}$ were negatively correlated (Fig. $2 \mathrm{C}$ ). 
Table 1

Baseline characteristics of the patients with CTEPH

CTEPH $(n=135)$

Age (years)

Male/Female, $n$

Body weight $(\mathrm{kg})$

BMI $\left(\mathrm{kg} / \mathrm{m}^{2}\right)$

WHO-FC (I: II: III: IV)

Type (Occult/Recurrent)

$\mathrm{Hb}(\mathrm{g} / \mathrm{dL})$

$\operatorname{BNP}(\mathrm{pg} / \mathrm{mL})$

CRP $(\mathrm{g} / \mathrm{dL})$

ATIII (\%)

Systolic blood pressure $(\mathrm{mmHg})$

Diastolic blood pressure $(\mathrm{mmHg})$

$\operatorname{mPAP}(\mathrm{mmHg})$

PVR (dyne $\llbracket \sec \llbracket \mathrm{cm}^{-5}$ )

$\operatorname{RAP}(\mathrm{mmHg})$

$\mathrm{CO}(\mathrm{L} / \mathrm{min})$

$\mathrm{Cl}\left(\mathrm{L} / \mathrm{min} / \mathrm{m}^{2}\right)$

$\mathrm{PaO}_{2}(\mathrm{mmHg})$

$\mathrm{PaCO}_{2}(\mathrm{mmHg})$

$\mathrm{PvO}_{2}(\mathrm{mmHg})$

$\mathrm{SvO}_{2}(\%)$
$64(52-70)$

$27 / 108$

$52.9(48.0-60.4)$

21.6 (20.0-23.8)

10:74:50:1

$80 / 55$

$13.8(12.6-14.8)$

86.3 (29.2-288)

$0.1(0.1-0.2)$

99 (89.8-109)

$124(110-142)$

73 (63-82)

$43(35-51)$

689 (482-983)

$8.0(6.0-11.5)$

$3.90(3.37-4.61)$

$2.53(2.18-2.95)$

$56(51.8-65.9)$

$37.7(34.3-42.7)$

$33.8(31.1-35.9)$

$62.7(58.5-68.5)$

Values are expressed as the median with the interquartile range. BMI, body mass index; WHO-FC, WHO -functional class; $\mathrm{Hb}$, hemoglobin; BNP, brain natriuretic peptide; CRP, C-reactive protein; ATIII, antithrombin III; mPAP, mean pulmonary arterial pressure; PVR, pulmonary vascular resistance; $\mathrm{CO}$, cardiac output; $\mathrm{Cl}$, cardiac index; $\mathrm{PaO}_{2}$, partial pressure of arterial oxygen; $\mathrm{PaCO}_{2}$, partial pressure of arterial carbon dioxide; $\mathrm{PvO}_{2}$, mixed venous oxygen pressure; $\mathrm{SvO}_{2}$, mixed venous oxygen saturation; $\mathrm{AaDO}_{2}$, alveolar-arterial oxygen difference; 6MWD, 6-minute walk distance; CTA, CT angiogram. 


\begin{tabular}{|c|c|}
\hline & CTEPH $(n=135)$ \\
\hline $\mathrm{AaDO}_{2}(\mathrm{mmHg})$ & $48.0(39.9-53.4)$ \\
\hline 6MWD (m) & $369(306-424)$ \\
\hline CTA obstruction score & $26(18-34)$ \\
\hline \multicolumn{2}{|c|}{$\begin{array}{l}\text { Values are expressed as the median with the interquartile range. } \mathrm{BMI} \text {, body mass index; WHO-FC, } \\
\text { WHO -functional class; } \mathrm{Hb} \text {, hemoglobin; } \mathrm{BNP} \text {, brain natriuretic peptide; } \mathrm{CRP}, \mathrm{C} \text {-reactive protein; } \mathrm{ATIII} \text {, } \\
\text { antithrombin III; } \mathrm{mPAP} \text {, mean pulmonary arterial pressure; } \mathrm{PVR} \text {, pulmonary vascular resistance; } \mathrm{CO} \text {, } \\
\text { cardiac output; } \mathrm{Cl} \text {, cardiac index; } \mathrm{PaO}_{2} \text {, partial pressure of arterial oxygen; } \mathrm{PaCO}_{2} \text {, partial pressure of } \\
\text { arterial carbon dioxide; } \mathrm{PvO}_{2} \text {, mixed venous oxygen pressure; } \mathrm{SvO}_{2} \text {, mixed venous oxygen saturation; } \\
\mathrm{AaDO}_{2} \text {, alveolar-arterial oxygen difference; } 6 \mathrm{MWD}, 6 \text {-minute walk distance; } \mathrm{CTA}, \mathrm{CT} \text { angiogram. }\end{array}$} \\
\hline
\end{tabular}


Table 2

Respiratory function indices in patients with CTEPH

\begin{tabular}{|c|c|c|c|}
\hline & Measured values & Expected values & p-value \\
\hline VC (L) & $2.55(2.05-3.07)$ & $2.57(2.33-2.92)$ & $<0.001^{* *}$ \\
\hline$\% \mathrm{VC}$ & $94.8(83.1-101.7)$ & & \\
\hline FVC (L) & $2.55(1.98-3.00)$ & $2.48(2.26-2.83)$ & $<0.001^{* *}$ \\
\hline$\% F V C$ & $94.6(84.2-105.1)$ & & \\
\hline $\mathrm{FEV}_{1.0}(\mathrm{~L})$ & $1.91(1.47-2.32)$ & $2.04(1.82-2,46)$ & $<0.001^{* *}$ \\
\hline $\mathrm{FEV}_{1.0} / \mathrm{FVC}(\%)$ & $76.0(70.0-82.1)$ & $81.9(79.3-85.9)$ & $<0.001^{* *}$ \\
\hline$\% \mathrm{FEV}_{1.0}$ & $83.6(73.8-98.3)$ & & \\
\hline MMF (L) & $1.40(0.87-2.17)$ & $2.60(2.30-3.10)$ & $<0.001^{* \star}$ \\
\hline$\% \mathrm{MMF}$ & $48.9(35.1-71.6)$ & & $<0.001^{* *}$ \\
\hline V50 & $2.02(1.28-2.75)$ & $2.95(2.66-3.5)$ & $<0.001^{* *}$ \\
\hline$\%$ V50 & $59.9(42.9-82.6)$ & & \\
\hline V25 (L) & $0.47(0.29-0.82)$ & $1.06(0.87-1.39)$ & $<0.001^{* *}$ \\
\hline$\%$ V25 & $41.8(29.0-58.5)$ & & \\
\hline PEF (L/s) & $5.54(4.42-6.67)$ & $5.62(5.37-6.08)$ & $<0.001^{* *}$ \\
\hline$>5 \%$ of $\mathrm{ATI}, \mathrm{n}(\%)$ & $24(17.8 \%)$ & & \\
\hline Restrictive ventilatory impairment, $\mathrm{n}(\%)$ & $22(16.3 \%)$ & & \\
\hline Obstructive ventilatory impairment, n (\%) & $34(25.2 \%)$ & & \\
\hline Mixed ventilatory impairment, n (\%) & $3(2.2 \%)$ & & \\
\hline $\mathrm{DLco}(\mathrm{mL} / \mathrm{min} / \mathrm{mmHg})$ & $13.1(10.9-16.0)$ & $17.0(15.1-20.1)$ & $<0.001^{* *}$ \\
\hline$\% D L c o$ & $77.0(64.8-86.5)$ & & \\
\hline TLC (L) & $4.77(3.92-5.64)$ & $4.44(4.11-4.97)$ & N.S \\
\hline $\mathrm{RV}(\mathrm{L})$ & $1.86(1.58-2.24)$ & $1.82(1.69-1.96)$ & N.S \\
\hline
\end{tabular}

Values are expressed as the median with the interquartile range. ${ }^{* *} p<0.01 . \mathrm{VC}$, vital capacity; $\mathrm{FEV}_{1.0}$, forced expiratory volume in 1 second; FVC, forced vital capacity; MMF, maximal mid-expiratory flow; PEF, peak expiratory flow; ATI, air trapping index; DLCo, diffused capacity of carbon monoxide; TLC, total lung capacity; RV, residual volume 


\section{Measured values Expected values}

p-value

$\mathrm{RV} / \mathrm{TLC}(\%)$

$39.9(35.4-43.9)$

Values are expressed as the median with the interquartile range ${ }^{* *} p<0.01$. VC, vital capacity; FEV 1.0 , forced expiratory volume in 1 second; FVC, forced vital capacity; MMF, maximal mid-expiratory flow; PEF, peak expiratory flow; ATI, air trapping index; DLco, diffused capacity of carbon monoxide; TLC, total lung capacity; RV, residual volume

Table 3

The correlation between PFT parameters and pulmonary hemodynamic parameters, CTA score at initial diagnosis

\begin{tabular}{|c|c|c|c|c|c|c|c|c|}
\hline & \multicolumn{2}{|c|}{$\% \mathrm{FEV}_{1.0}$} & \multicolumn{2}{|c|}{$\%$ MMF } & \multicolumn{2}{|l|}{$\%$ V50 } & \multicolumn{2}{|l|}{$\%$ V25 } \\
\hline & $r$ & $\mathrm{p}$ & $r$ & $\mathrm{p}$ & $r$ & $\mathrm{p}$ & $r$ & $\mathrm{p}$ \\
\hline पPAP & -0.266 & $0.002^{*}$ & -0.204 & $0.0177^{\star}$ & -0.271 & $0.0015^{\star}$ & -0.194 & $0.0244^{*}$ \\
\hline PVR & -0.284 & $0.0009^{\star *}$ & -0.223 & $0.0096^{\star \star}$ & -0.241 & 0.0051 & -0.195 & $0.0245^{*}$ \\
\hline $\mathrm{CO}$ & 0.127 & 0.1408 & 0.176 & $0.0410^{*}$ & 0.137 & 0.113 & 0.152 & 0.0797 \\
\hline $\mathrm{Cl}$ & 0.219 & $0.0109^{*}$ & 0.216 & $0.0121^{*}$ & -0.186 & $0.0306^{*}$ & 0.229 & $0.0078^{* x}$ \\
\hline CTA & -0.445 & $<0.0001$ & -0.203 & $0.0181^{*}$ & -0.256 & $0.0028^{*}$ & -0.132 & 0.127 \\
\hline
\end{tabular}

${ }^{*} p<0.05 ;{ }^{* *} p<0.01$. PFT, pulmonary function test; mPAP, mean pulmonary arterial pressure; PVR, pulmonary vascular resistance; $\mathrm{CO}$, cardiac output; $\mathrm{Cl}$, cardiac index; CTA, CTA obstruction score; FEV 1.0 , forced expiratory volume in 1 second; FVC, forced vital capacity; MMF, maximal mid-expiratory flow 
Table 4

Baseline characteristics and respiratory function indices subdivided into groups according to median mean $\% \mathrm{FEV}_{1.0}$

\begin{tabular}{|c|c|c|c|}
\hline & $\% \mathrm{FEV}_{1.0} \triangle 83.6 \%$ & $\% \mathrm{FEV}_{1.0} \geqq 83.6 \%$ & p-value \\
\hline Age (years) & $58.7 \pm 1.7$ & $62.2 \pm 1.4$ & N.S \\
\hline Male/Female, $n$ & $19 / 48$ & $8 / 60$ & 0.0148 \\
\hline Body weight (kg) & $57.2 \pm 1.5$ & $52.8 \pm 1.05$ & 0.0339 \\
\hline BMI $\left(\mathrm{kg} / \mathrm{m}^{2}\right)$ & $22.4 \pm 0.5$ & $21.8 \pm 0.3$ & N.S \\
\hline WHO-FC (I: II: III: IV) & $6 / 34 / 26 / 1$ & $4 / 40 / 24 / 0$ & N.S \\
\hline Type (Occult/Recurrent) & $40 / 27$ & $40 / 28$ & N.S \\
\hline $\mathrm{Hb}(\mathrm{g} / \mathrm{dL})$ & $13.9 \pm 0.2$ & $13.6 \pm 0.2$ & N.S \\
\hline BNP (pg/mL) & $296 \pm 51$ & $162 \pm 27$ & 0.0098 \\
\hline $\mathrm{CRP}(\mathrm{g} / \mathrm{dL})$ & $0.27 \pm 0.06$ & $0.21 \pm 0.05$ & 0.0173 \\
\hline ATIII (\%) & $97.4 \pm 1.8$ & $100.3 \pm 1.6$ & N.S \\
\hline Systolic SBP & $123 \pm 3$ & $129 \pm 2$ & 0.0346 \\
\hline Diastolic SBP & $73 \pm 2$ & $74 \pm 2$ & N.S \\
\hline mPAP $(\mathrm{mmHg})$ & $45.1 \pm 1.3$ & $41.1 \pm 1.2$ & 0.0331 \\
\hline PVR (dyne $\llbracket \sec \llbracket \mathrm{cm}^{-5}$ ) & $815 \pm 45$ & $689 \pm 34$ & 0.0334 \\
\hline $\mathrm{RAP}(\mathrm{mmHg})$ & $10.1 \pm 0.53$ & $7.65 \pm 0.43$ & 0.0008 \\
\hline $\mathrm{CO}(\mathrm{L} / \mathrm{min})$ & $4.05 \pm 0.14$ & $4.23 \pm 0.13$ & N.S \\
\hline $\mathrm{Cl}\left(\mathrm{L} / \mathrm{min} / \mathrm{m}^{2}\right)$ & $2.51 \pm 0.08$ & $2.77 \pm 0.09$ & 0.0307 \\
\hline CTA obstruction score & $30.1 \pm 1.3$ & $21.6 \pm 1.2$ & $<0.0001$ \\
\hline
\end{tabular}


Table 5

Predictors of low $\% \mathrm{FEV}_{1}$ according to a multivariate logistic regression analysis

Predictors of low \%FEV 1.0

\begin{tabular}{|c|c|c|c|c|c|c|}
\hline & Univariate & & & Multivariat & & \\
\hline & Odds ratio & $95 \% \mathrm{Cl}$ & p-value & Odds ratio & $95 \% \mathrm{Cl}$ & p-value \\
\hline BW & 1.041 & $1.006-1.077$ & $0.0170^{*}$ & 1.031 & $0.981-1.084$ & 0.214 \\
\hline BNP & 1.001 & $1.000-1.003$ & $0.0164^{*}$ & 1.000 & $0.999-1.002$ & 0.809 \\
\hline CRP & 1.369 & $0.596-3.144$ & 0.443 & & & \\
\hline sBP & 0.984 & $0.967-1.001$ & 0.0627 & & & \\
\hline mPAP & 1.041 & $1.005-1.078$ & $0.020^{*}$ & 1.073 & $0.980-1.174$ & 0.124 \\
\hline PVR & 1.001 & $1.000-1.002$ & $0.0267^{*}$ & 0.998 & $0.994-1.002$ & 0.267 \\
\hline $\mathrm{Cl}$ & 0.560 & $0.329-0.952$ & $0.0266^{*}$ & 0.369 & $0.119-1.143$ & 0.076 \\
\hline RAP & 1.182 & $1.071-1.305$ & $0.0003^{* \star}$ & 1.071 & $0.951-1.208$ & 0.256 \\
\hline CTA & 1.084 & $1.044-1.126$ & $<0.0001^{* *}$ & 1.074 & $1.031-1.120$ & $<0.001^{\star \star}$ \\
\hline
\end{tabular}

\section{Discussion}

In the present study we analyzed $135 \mathrm{CTEPH}$ patients and found that a decreased $\% \mathrm{FEV}_{1.0}$ and $\% \mathrm{MMF}$ were correlated with the degree of vascular obstruction and pulmonary hemodynamics. On analyzing the CTA obstruction score, pulmonary hemodynamics and PFT parameters one year after PEA, the \%FEV 1.0 was found to be improved with the improvement of CTA obstruction score and pulmonary hemodynamics. The improvement of the $\% \mathrm{FEV}_{1.0}$ due to the improvement of vascular occlusion or stenosis is consistent with the findings of a previous study by Takei et al. describing balloon pulmonary angioplasty cases [20]. Those findings suggest that the obstructive impairment in CTEPH patients might have an etiological correlation with the degree of vascular obstruction.

The present findings newly suggest that airway obstruction has an etiological correlation with vascular involvement in CTEPH. We excluded the CTEPH patients who had a smoking history in order to exclude obstructive impairment due to COPD as much as possible. In a previous case report, a CTEPH patient was misdiagnosed with bronchial asthma because of exertional dyspnea and a low $\mathrm{FEV}_{1.0}$ [8]. A low FEV 1.0 does not necessarily mean the presence of airway disease such as COPD and asthma in patients having 
exertional dyspnea. We should keep the possibilities of the pathophysiological condition with right heart burden including CTEPH in mind while carrying out a physical examination, chest X-ray, electrocardiogram, etc.

Summarizing the previous studies, the pathological changes in CTEPH are characterized by thrombotic occlusion and remodeling of non-obstructed arteries induced by the flow diversion from obstructed arteries [21, 22]. In the area where pulmonary arteries are occluded, peripheral opacites caused by infarction are frequent findings on chest CT $[23,24]$. Lung infarction could affect local airflow by collapsing the alveolar- bronchiole regions. On the other side, many papers described that the disparity in segmental vessel size reflecting the irregular distribution of emboli within the lungs was a characteristic finding of the CTEPH $[23,25,26]$. Local enlargement of the peripheral pulmonary arteries may lead to compression of bronchi nearby.

Another possible important factor of flow limitation underlying CTEPH is the concept of "inflammatory thrombosis". Various inflammatory substances are reportedly generated from blood clots and remodeled pulmonary arteries, including CRP [27], TNF-a [28], and MCP-1 [29]. These cytokines are also reported to enhance the bronchial contraction [30-32]. In our results, significant correlation was observed between CTA obstruction score and the \%FEV 1.0 (Fig. 1). Inflammatory cytokines from blood clots in the subsegmental pulmonary arteries might lead to contraction of bronchioles nearby.

This is the first report to evaluate the respiratory impedance in patients with CTEPH, although the respiratory impedance parameters were poorly correlated with the spirometry parameters. The FOT is a method of measuring the lung mechanics that is better at the early detection of flow limitation than spirometry [33-35]. The correlation between the FOT and spirometry parameters has been previously reported. In COPD and asthma, R5 moderately correlates with the FEV ${ }_{1.0}$ and is thus used as an index of airway obstruction [36-38]. X5, Fres, and ALX are indicators of resistance of lung expansion or shrinkage and reflect abnormalities of the lung parenchyma [37]. In the present study, the FOT parameters were poorly correlated with spirometry, in contrast to the previous studies mentioned above (Additional File 1). Because the respiratory impedance in CTEPH patients showed differing trends from those in COPD or asthma [37, 38], there might be an etiological difference between the obstructive impairment seen in CTEPH and that in COPD/asthma. Further investigations will help clarify the entire CTEPH etiology.

Several limitations associated with the present study warrant mention. First, the study design was a retrospective, single-center, observational study. Second, we were unable to clarify the detailed mechanism underlying the respiratory function changes because we were unable to perform pathological analyses. An additional multicenter investigation is therefore required.

\section{Conclusion}

In CTEPH patients without a smoking history, the $\% \mathrm{FEV}_{1.0}$ showed a significant correlation with the pulmonary arterial obstruction and the pulmonary hemodynamics. Obstructive impairment might have an 
etiological relationship with vascular involvement. A further investigation focusing on the obstructive impairment in CTEPH patients may shed new light on the CTEPH etiology.

\section{Abbreviations}

CTEPH

Chronic thromboembolic pulmonary hypertension

$\mathrm{RHC}$

right heart catheterization

mPAP

mean pulmonary artery pressure

PVR

pulmonary vascular resistance

CO

cardiac output

$\mathrm{Cl}$

cardiac index

CTA

CT Angiogram

PFT

pulmonary function test

VC

vital capacity

FVC

forced vital capacity

$\mathrm{FEV}_{1.0}$

forced expiratory volume in one second

MMF

maximum mid-expiratory flow

PEF

peak expiratory flow

DLCO

diffusion capacity for carbon monoxide

FOT

multi-frequency forced oscillation technique

Rrs

respiratory system resistance

Xrs

respiratory system reactance

R5 
respiratory system resistance at $5 \mathrm{~Hz}$

R20

respiratory system resistance at $20 \mathrm{~Hz}$

R5 - R20

the difference between the R5 and R20

PEA

pulmonary endarterectomy

\section{Declarations}

Ethics approval and consent to participate

This retrospective, observational study protocol was approved by the institutional review board of Chiba University (approval number 2584).

Consent for publication

Not applicable

Availability of data and materials

The datasets used and/or analyzed during the current study are available from the corresponding author on reasonable request.

Competing interests.

The authors declare that they have no competing interests.

\section{Funding}

Not applicable

Authors' contributions

AY, AN were involved in study design and data interpretation. AY, AN, TS were involved in the data analysis. TJS, HK, RS, AS were involved in the acquisition of the data from clinical database. $\mathrm{KI}$ and $\mathrm{GM}$ were involved in the data analysis of pulmonary endarterectomy. AY, AN wrote the main manuscript, and NT, KT, TS critically revised the report, commented on drafts of the manuscript. All authors approved the final report.

\section{Acknowledgements}

This study was supported in part by grants from the Intractable Respiratory Diseases and Pulmonary Hypertension Research Group, the Ministry of Health, Labor and Welfare, Japan (2020-2022). We thank the technical staff of Chiba University Hospital for performing the respiratory impedance analysis. 


\section{References}

1. Witkin AS, Channick RN: Chronic Thromboembolic Pulmonary Hypertension: the End Result of Pulmonary Embolism. Curr Cardiol Rep 2015, 17:63.

2. Lang IM, Pesavento R, Bonderman D, Yuan JX: Risk factors and basic mechanisms of chronic thromboembolic pulmonary hypertension: a current understanding. Eur Respir J 2013, 41:462-468.

3. Haoming S, Lemin W, Zhu G, Aibin L, Yuan X, Wei L et al: T cell-mediated immune deficiency or compromise in patients with CTEPH. Am J Respir Crit Care Med 2011, 183:417-418.

4. Bonderman D, Wilkens $\mathrm{H}$, Wakounig S, Schäfers HJ, Jansa P, Lindner $\mathrm{J}$ et al: Risk factors for chronic thromboembolic pulmonary hypertension. Eur Respir J 2009, 33:325-331.

5. Fernandes T, Auger W, Fedullo P: Epidemiology and risk factors for chronic thromboembolic pulmonary hypertension. Thromb Res 2018, 164:145-149.

6. Palkar AV, Agrawal A, Verma S, Iftikhar A, Miller EJ, Talwar A: Post splenectomy related pulmonary hypertension. World J Respirol 2015, 5:69-77.

7. Yan L, Li X, Liu Z, Zhao Z, Luo Q, Zhao Q et al: Research progress on the pathogenesis of CTEPH. Heart Fail Rev 2019, 24:1031-1040.

8. Sato S, Sugiura T, Tanabe N, Terada J, Sakao S, Kasahara Y et al: Successful operative case of chronic thromboembolic pulmonary hypertension clinically diagnosed as bronchial asthma. Nihon Kokyuki Gakkai Zasshi 2010, 48:836-841.

9. Fukushi K, Kataoka M, Shimura N, Inami T, Fukuda K, Yoshino H et al: Impaired Respiratory Function in Chronic Thromboembolic Pulmonary Hypertension: A Comparative Study with Healthy Control Subjects. Ann Am Thorac Soc 2016, 13:1183-1184.

10. Galiè N, Humbert M, Vachiery JL, Gibbs S, Lang I, Torbicki A et al: 2015 ESC/ERS Guidelines for the diagnosis and treatment of pulmonary hypertension: The Joint Task Force for the Diagnosis and Treatment of Pulmonary Hypertension of the European Society of Cardiology (ESC) and the European Respiratory Society (ERS): Endorsed by: Association for European Paediatric and Congenital Cardiology (AEPC), International Society for Heart and Lung Transplantation (ISHLT). Eur Heart J 2016, 37:67-119.

11. Jujo T, Sakao S, Ishibashi-Ueda H, Ishida K, Naito A, Sugiura T et al: Evaluation of the Microcirculation in Chronic Thromboembolic Pulmonary Hypertension Patients: The Impact of Pulmonary Arterial Remodeling on Postoperative and Follow-Up Pulmonary Arterial Pressure and Vascular Resistance. PLoS One 2015, 10:e0133167.

12. Qanadli SD, El Hajjam M, Vieillard-Baron A, Joseph T, Mesurolle B, Oliva VL et al: New CT Index to Quantify Arterial Obstruction in Pulmonary Embolism. American Journal of Roentgenology 2001, 176:1415-1420.

13. Jujo T, Tanabe N, Sakao S, Ishibashi-Ueda H, Ishida K, Naito A et al: Severe Pulmonary Arteriopathy Is Associated with Persistent Hypoxemia after Pulmonary Endarterectomy in Chronic Thromboembolic Pulmonary Hypertension. PloS one 2016, 11:e0161827-e0161827. 
14. Anazawa R, Kawata N, Matsuura Y, Ikari J, Tada Y, Suzuki M et al: Longitudinal changes in structural lung abnormalities using MDCT in chronic obstructive pulmonary disease with asthma-like features. PLoS One 2019, 14:e0227141.

15. Sakurai-lesato Y, Kawata N, Tada Y, lesato K, Matsuura Y, Yahaba M et al: The Relationship of Bone Mineral Density in Men with Chronic Obstructive Pulmonary Disease Classified According to the Global Initiative for Chronic Obstructive Lung Disease (GOLD) Combined Chronic Obstructive Pulmonary Disease (COPD) Assessment System. Intern Med 2017, 56:1781-1790.

16. Miller MR, Hankinson J, Brusasco V, Burgos F, Casaburi R, Coates A et al: Standardisation of spirometry. Eur Respir J 2005, 26:319-338.

17. Kubota M, Kobayashi $H$, Quanjer PH, Omori H, Tatsumi K, Kanazawa M: Reference values for spirometry, including vital capacity, in Japanese adults calculated with the LMS method and compared with previous values. Respir Investig 2014, 52:242-250.

18. [Guideline of respiratory function tests-spirometry, flow-volume curve, diffusion capacity of the lung]. Nihon Kokyuki Gakkai Zasshi 2004, Suppl:1-56.

19. Oostveen E, MacLeod D, Lorino H, Farré R, Hantos Z, Desager K et al: The forced oscillation technique in clinical practice: methodology, recommendations and future developments. Eur Respir J 2003, 22:1026-1041.

20. Takei M, Kawakami T, Kataoka M, Kuwahira I, Fukuda K: Residual high intrapulmonary shunt fraction limits exercise capacity in patients treated with balloon pulmonary angioplasty. Heart Vessels 2019, 34:868-874.

21. Moser KM, Bloor CM: Pulmonary vascular lesions occurring in patients with chronic major vessel thromboembolic pulmonary hypertension. Chest 1993, 103:685-692.

22. Lang IM, Dorfmüller P, Vonk Noordegraaf A: The Pathobiology of Chronic Thromboembolic Pulmonary Hypertension. Ann Am Thorac Soc 2016, 13 Suppl 3:S215-221.

23. Bergin CJ, Rios G, King MA, Belezzuoli E, Luna J, Auger WR: Accuracy of high-resolution CT in identifying chronic pulmonary thromboembolic disease. AJR Am J Roentgeno/ 1996, 166:13711377.

24. Grosse $C$, Grosse A: CT findings in diseases associated with pulmonary hypertension: a current review. Radiographics 2010, 30:1753-1777.

25. Grosse A, Grosse C, Lang IM: Distinguishing Chronic Thromboembolic Pulmonary Hypertension From Other Causes of Pulmonary Hypertension Using CT. AJR Am J Roentgeno/ 2017, 209:1228-1238.

26. Grosse A, Grosse C, Lang I: Evaluation of the $C T$ imaging findings in patients newly diagnosed with chronic thromboembolic pulmonary hypertension. PloS one 2018, 13:e0201468-e0201468.

27. Quarck R, Nawrot T, Meyns B, Delcroix M: C-reactive protein: a new predictor of adverse outcome in pulmonary arterial hypertension. J Am Coll Cardiol 2009, 53:1211-1218.

28. Langer F, Schramm R, Bauer M, Tscholl D, Kunihara T, Schäfers HJ: Cytokine response to pulmonary thromboendarterectomy. Chest 2004, 126:135-141. 
29. Kimura H, Okada O, Tanabe N, Tanaka Y, Terai M, Takiguchi Y et al: Plasma monocyte chemoattractant protein-1 and pulmonary vascular resistance in chronic thromboembolic pulmonary hypertension. Am J Respir Crit Care Med 2001, 164:319-324.

30. Chen $\mathrm{H}$, Tliba O, Van Besien CR, Panettieri RA, Jr., Amrani Y: TNF-[alpha] modulates murine tracheal rings responsiveness to G-protein-coupled receptor agonists and KCl. J Appl Physiol (1985) 2003, 95:864-872; discussion 863.

31. Goto K, Chiba Y, Matsusue K, Hattori Y, Maitani Y, Sakai H et al: The proximal STAT6 and NF-kappaB sites are responsible for IL-13- and TNF-alpha-induced RhoA transcriptions in human bronchial smooth muscle cells. Pharmacol Res 2010, 61:466-472.

32. Kudo M, Khalifeh Soltani SM, Sakuma SA, McKleroy W, Lee TH, Woodruff PG et al: Mfge8 suppresses airway hyperresponsiveness in asthma by regulating smooth muscle contraction. Proc Natl Acad Sci U S A 2013, 110:660-665.

33. Frantz $S$, Nihlén U, Dencker M, Engström G, Löfdahl CG, Wollmer P: Impulse oscillometry may be of value in detecting early manifestations of COPD. Respir Med 2012, 106:1116-1123.

34. Nilsson AM, Theander E, Hesselstrand R, Piitulainen E, Wollmer P, Mandl T: The forced oscillation technique is a sensitive method for detecting obstructive airway disease in patients with primary Sjogren's syndrome. Scand J Rheumatol 2014, 43:324-328.

35. Cottee AM, Seccombe LM, Thamrin C, King GG, Peters MJ, Farah CS: Bronchodilator Response Assessed by the Forced Oscillation Technique Identifies Poor Asthma Control With Greater Sensitivity Than Spirometry. Chest 2020, 157:1435-1441.

36. Shirai T, Mori K, Mikamo M, Shishido Y, Akita T, Morita S et al: Respiratory mechanics and peripheral airway inflammation and dysfunction in asthma. Clin Exp Allergy 2013, 43:521-526.

37. Shirai T, Kurosawa H: Clinical Application of the Forced Oscillation Technique. Intern Med 2016, 55:559-566.

38. Mori K, Shirai T, Mikamo M, Shishido Y, Akita T, Morita S et al: Colored 3-dimensional analyses of respiratory resistance and reactance in COPD and asthma. Copd 2011, 8:456-463.

\section{Figures}




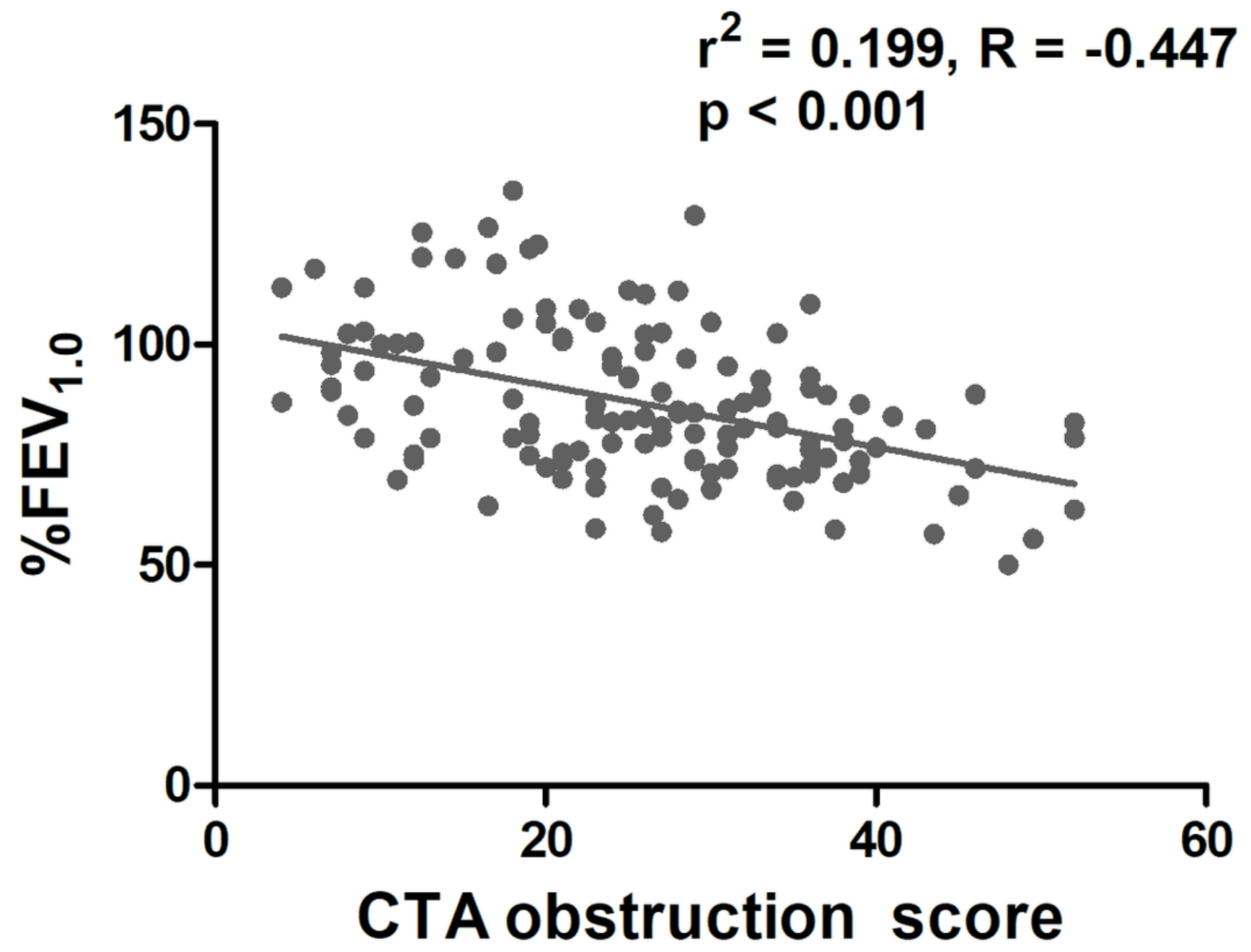

Figure 1

The correlation between CTA obstruction score and \%FEV1.0 The CT angiogram obstruction score was defined as the total score of each sub-segmental pulmonary arteries (score 0: no thrombi; score 1: the artery was narrowed by chronic thrombi but contrast medium passed to distal areas; score 2: the artery was obstructed by chronic thrombi and contrast medium did not pass to distal areas). Significant correlation was observed between CTA obstruction score and the \%FEV1.0.
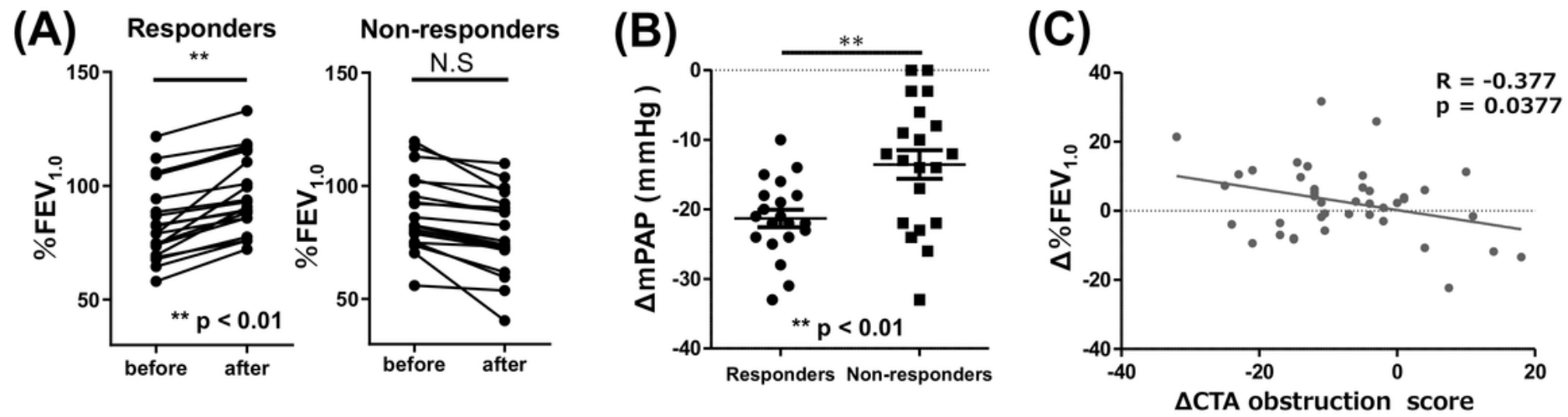


\section{Figure 2}

A)Change in \%FEV1.0 of responders and non-responders group. B) Effect of PEA on improvement of mPAP $(\triangle \mathrm{mPAP})$ between responders and non-responders. C) The correlation between $\triangle \mathrm{CTA}$ obstruction score and $\triangle \% \mathrm{FEV} 1.0$ The largest 20 cases regarding the value of \%FEV1.0 positive and negative difference before and after PEA was defined as responder and non-responder, respectively. A) The difference in value was named as $\triangle \% F E V 1.0$. B) Mean PAP was better improved in the responders group compared to the non-responders group. C) In 29 patients in whose CTA obstruction score could be assessed postoperatively, $\triangle \mathrm{CTA}$ obstruction score and $\triangle \% \mathrm{FEV} 1.0$ were negatively correlated.

\section{Supplementary Files}

This is a list of supplementary files associated with this preprint. Click to download.

- Additionalfile1.docx

- Additionalfile2.docx

- Additionalfile3.docx 